\title{
A Study on Mediating Effects of Social Supports between Job Characteristics and the Quality of Life of the Elderly Single Household Caregiver
}

\author{
Dae-Ju Lee ${ }^{1)}$, Sung-je $\mathrm{Cho}^{2)}$ \\ 독거노인생활관리사의 직무 특성과 삶의 질 관계에서 \\ 사회적 지지 매개효과에 관한 연구 \\ 이대주1), 조성제2)
}

\begin{abstract}
The purpose of this study is to investigate the mediating effects of social support on the relationship between job characteristics and quality of life of elderly single household caregivers. The subjects of this study were 174 elderly single household caregivers in Daegu. For the analysis method, frequency analysis, reliability analysis, and correlation analysis were performed using SPSS 22.0 program, and multiple regression analysis was performed for mediating effects. As a result, first, social support had a partial mediating effect on the relationship between job identity and physical quality of life among the subordinate factors of job characteristics of elderly single household caregivers. Second, it was confirmed that social support has a completely mediating effect on the relationship between job identity and mental quality of life among sub-factors of job characteristics perceived by the elderly single household caregivers. Third, among the sub-factors of job characteristics perceived by elderly single household caregivers, social support had a partial mediating effect on the relationship between job identity and socioeconomic quality of life. This study is considered to be the basic data for the improvement of work environment of elderly single household caregivers.
\end{abstract}

Keywords: The Elderly Single Household Caregiver, Job Characteristics, Social Support, Quality of Life

Received(February 07, 2020), Review Result(1st: March 10, 2020, 2nd: May 01, 2020), Accepted(May 27, 2020)

1) (Ph.D. course/doctorate course) 02838 Dept. of Culture and Art, Dongbang Culture Graduate University, 28 Sungbok-Ro, Sungbokdong, Seoul, Korea

email: jesus9106@naver.com

2) (Professor, Corresponding Author) 02838 Dept. of Culture and Art, Dongbang Culture Graduate University, Dongbang Culture Graduate Univ., 28 Sungbok-Ro, Sungbokdong, Seoul, Korea

email: chosj715@daum.net 


\section{A Study on Mediating Effects of Social Supports between Job Characteristics and the Quality of Life of the Elderly Single Household Caregiver}

요 약

본 연구의 목적은 독거노인생활관리사의 직무 특성과 삶의 질과의 관계에서 사회적 지지의 매개효과 에 대하여 파악하는 데 있다. 연구대상은 대구광역시의 독거노인생활관리사 174 명을 대상으로 실시하 였다. 분석방법은 SPSS 22.0 프로그램을 사용하여 신뢰도 분석과 빈도 분석을 실시하였다. 또한 상관 분석과 다중회귀분석을 수행하였다. 연구결과 첫째, 독거노인생활관리사의 직무 특성 하위요인 중 직 무 정체성과 신체적 삶의 질과의 관계에서 사회적 지지는 부분 매개효과가 있는 것으로 나타났다. 둘 째, 독거노인생활관리사가 지각하는 직무 특성의 하위요인 중 직무 정체성과 정신적 삶의 질과의 관 계에서 사회적 지지는 완전 매개효과가 있는 것으로 확인되었다. 셋째, 독거노인생활관리사가 지각하 는 직무 특성의 하위요인 중 직무 정체성과 사회경제적 삶의 질과의 관계에서 사회적 지지는 부분 매개효과가 있는 것으로 파악되었다. 본 연구는 독거노인생활관리사들의 직무환경에 대한 개선방안 마련의 기초자료가 될 것으로 사료된다.

핵심어: 독거노인생활관리사, 직무 특성, 사회적 지지, 삶의 질

\section{1. 서론}

\section{1 연구의 필요성}

최근 급격한 노인 인구 증가 및 핵가족 등으로 노인부양의식 변화로 인하여 홀로 살아가는 독거노 인 인구가 증가 되고 있다. 통계청 자료에 의하면, 2000 년도 $3.8 \%$ 에서 2017 년도 $7.0 \%$ 로 독거노인 가구 비율이 매년 증가추세이다. 또한 핵가족으로 인한 가족의 분화가 이루어지면서 가족에 결속 도가 떨어지고 배우자의 사망이나 경제 이유로 가족과 떨어져 있는 독거노인이 증가되고 있다[1]. 이러한 독거노인은 경제적 상실 문제, 질병, 역할상실, 부양문제, 고독감 등으로 스트레스에 노출되 고 있으며, 독거노인의 스트레스는 노인의 삶의 질에 부정적인 영향을 미치는 것으로 나타났다[2]. 한편 독거노인의 거주특성 및 생활환경의 특성상 타인을 포함한 사회와의 교류가 잘 이루어지기 어렵다. 이와 같은 사회와의 교류 단절은 고독사라는 심각한 사회적 문제로 이어지고 있다고 할 수 있다[3]. 따라서 독거노인들이 거주특성 및 생활환경 내에서 독립적인 생활을 유지하기 위해 도 움을 줄 수 있는 독거노인생활관리사가 절실히 요구된다.

독거노인보호사업을 수행하는 독거노인생활관리사는 독거노인의 돌봄 서비스를 수행과 동시에 응급안전에 돌봄 업무를 통해 대상자의 행복한 삶을 증진시키는 것이 주 업무이다. 한편 독거노인 생활관리사는 타 직종 종사자들보다 더 낮은 사회적 인식과 열악한 근무환경 등으로 많은 어려움 에 노출되고 있다[4]. 이러한 결과는 독거노인생활관리사의 감정노동은 심리적 소진에 영향을 미치 는 것으로 판단된다. 즉 감정노동이 높을수록 심리적 소진이 높아진다는 연구결과가 지지하고 있다 [5]. 이러한 심리적 소진은 노인돌봄기본서비스, 독거노인 응급안전 돌봄서비스 등을 통해 독거노인 의 삶의 질에 영향을 미치는 요인이 된다. 이러한 문제를 해결하기 위해서는 사회적 지지가 중요하 다고 보고되고 있다[6]. 요양보호사를 대상으로 사회적 지지가 삶의 질에 대한 분석결과, 상사 지지 는 요양보호사의 환경, 신체 삶의 질에 영향을 미치고, 동료 지지는 사회, 신체 삶의 질에 영향을 미쳤다[7]는 것이 확인되었다. 또한 사회적 지지가 심리 소진을 통계적으로 유의미하게 영향을 미치 

고 있는 것으로 나타났다[6]. 이러한 결과는 독거노인의 서비스의 질 개선은 독거노인생활관리사의 사회적 지지가 중요함을 알 수 있다. 그 이유로 독거노인생활관리사가 제공하는 서비스 질에 영향 을 미치는 요인으로 근무기간, 자아효능감, 사회적 지지, 직무스트레스 등이 있는 것으로 나타났다 [8]. 특히 이러한 요인 중에서 사회적 지지는 독거노인생활관리사가 제공하는 서비스 질에 영향을 미치는 요인임을 알 수 있다. 따라서 독거노인의 노인돌봄기본서비스, 독거노인 응급안전 돌봄서비 스 질 향상을 위해 독거노인생활관리사의 삶의 질을 향상시키기 위한 방안들의 연구가 필요하다.

직무 환경과 삶의 질에 대한 연구결과를 보면, 직장 생활의 질과 삶의 질의 관계에서도 긍정적 인 영향을 미치는 것으로 확인되었다. 특히, 직무관련 삶의 질을 매개하여 서비스 질에 영향력을 주는 것은 직무관련 삶의 질(공감만족)이었다고 밝혔다[9]. 또한, 삶의 질의 요인으로 주목받고 있 는 개념의 하나로서 사회적 지지가 보고되고 있다. 사회적 지지가 삶의 질에 미치는 영향에 한 선 행연구를 살펴보면, 삶의 질은 사회지지와 정 $(+)$ 적 상관관계를 나타낸 반면, 사회지지가 낮을수록 삶의 질을 저하시키는 효과가 있는 것으로 보고되고 있다[10]. 따라서 독거노인생활관리사의 삶의 질을 증진시키기 위해서는 직무 특성요인과 사회적 지지의 향상을 위한 구체적인 방안을 모색할 필요가 있다고 판단된다.

이러한 선행연구결과를 토대로 직무 특성과 사회적 지지가 독거노인생활관리사의 삶의 질에 미 치는 영향에 대한 연구의 필요성이 대두된다. 기존연구에서는 독거노인을 대상으로 건강상태에 관 한 연구와 관련된 연구가 일부 진행되었지만, 독거노인생활관리사를 대상으로 삶의 질에 관한 연 구는 찾아보기 어렵다. 따라서 본 연구는 직무 특성과 사회적 지지가 독거노인생활관리사의 삶의 질에 미치는 영향을 밝힘으로써 독거노인생활관리사들의 심리적 안녕감 향상 방안을 위한 기초자 료를 제공하고자 한다. 이와 같은 연구를 시작하게 된 직접적인 동기는 연구자가 25년여 동안 노인 복지시설 등과 기타 사회복지시설에 근무하면서 특히 독거노인기본서비스수행기관에 근무하면서 전 체직원의 $90 \%$ 이상 차지하는 독거노인생활관리사들의 직무에 대한 고민과 역할 그리고 동기부여에 대한 필요성이 대두되어 직무특성과 사회적 지지, 삶의 질에 대한 연구를 하게 되었다.

\section{2 연구문제}

본 연구의 목적은 독거노인생활관리사의 직무 특성과 삶의 질의 관계에서 사회적 지지의 매개효과 에 대하여 분석하고자 한다. 이에 대한 연구문제는 다음과 같다.

첫째, 독거노인생활관리사의 직무 특성과 신체적 삶의 질과의 관계에서 사회적 지지의 매개효과 는 어떠한가?

둘째, 독거노인생활관리사의 직무 특성과 정신적 삶의 질과의 관계에서 사회적 지지의 매개효과 는 어떠한가?

셋째, 독거노인생활관리사의 직무 특성과 사회경제적 삶의 질과의 관계에서 사회적 지지의 매개 효과는 어떠한가? 


\section{2. 연구방법}

\section{1 연구대상}

본 연구는 2019년 9월 23일부터 2019년 11월 22일까지 대구광역시 6개구 독거노인기본서비스수행 기관 독거노인생활관리사를 대상으로 직접 설문조사하였다. 설문조사는 설문대상자에게 설문내용 을 상세히 설명한 후 설문을 수행하였다. 설문조사를 총 180 부 수집한 후 불성실한 설문지 6 부를 제외한 174 부를 통계자료에 적용하였다.

\section{2 연구도구}

본 연구에 사용된 도구는 인구사회학적 특성 5 문항, 직무 특성 12 문항, 사회적 지지 25 문항, 삶의 질 40 문항으로 구성하였다. 인구사회학적 특성에 관한 내용은 성별, 연령, 결혼상태, 종교유무, 근 무경력 등으로 구성하여 조사하였다. 독거노인생활관리사의 직무 특성을 측정하기 위해 김부열[11] 이 사용한 직무 특성의 측정도구는 하위요인 직무 다양성 3 문항, 직무 정체성 3 문항, 직무 중요성 3 문항, 직무 자율성 3 문항 총 12 문항으로 설계하였다. 각 설문문항은 리커트 5점 척도로 구성하였 다. 그리고 독거노인생활관리사의 사회적 지지를 측정하기 위해 김기순[12]이 사용한 척도를 사용 하였다. 설문문항은 정서적 지지 7문항으로, 정보적 지지 6문항으로, 물질적 지지 6문항으로, 평가 적 지지 6문항으로 설계하였다. 또한, 독거노인생활관리사의 삶의 질을 측정하기 위해 구택회[13] 가 사용한 척도를 사용하였다. 설문문항은 신체적 삶의 질 5 문항으로, 정신적 삶의 질 5 문항으로, 사회경제적 삶의 질 5 문항으로 설계하였다. 각 설문문항은 리커트 5점 척도로 구성하였다.

\section{3 신뢰도}

본 연구에 사용된 각 변수의 신뢰도 검증결과 직무 특성의 하위요인인 직무 다양성 .627, 직무 중 요성 .715, 직무 자율성 .646, 직무 정체성 .618 전체 신뢰도 .683의 신뢰도를 보이고 있다. 사회적 지지에 대한 신뢰도는 하위요인인 정서적 지지 .822. 정보적 지지 .788, 물질적 지지 .886, 평가적 지지 .799 전체 .860 의 높은 신뢰도를 보이고 있다. 삶의 질에 대한 신뢰도는 하위요인인 신체적 삶의 질 .875 , 정신적 삶의 질 .860 , 사회경제적 삶의 질 .817 전체 신뢰도 .897 로 높게 나타났다. 신뢰도 분석결과는 [표 1]과 같이 나타났다. 
[표 1] 주요 변수의 신뢰도

[Table 1] Reliability of Key Variables

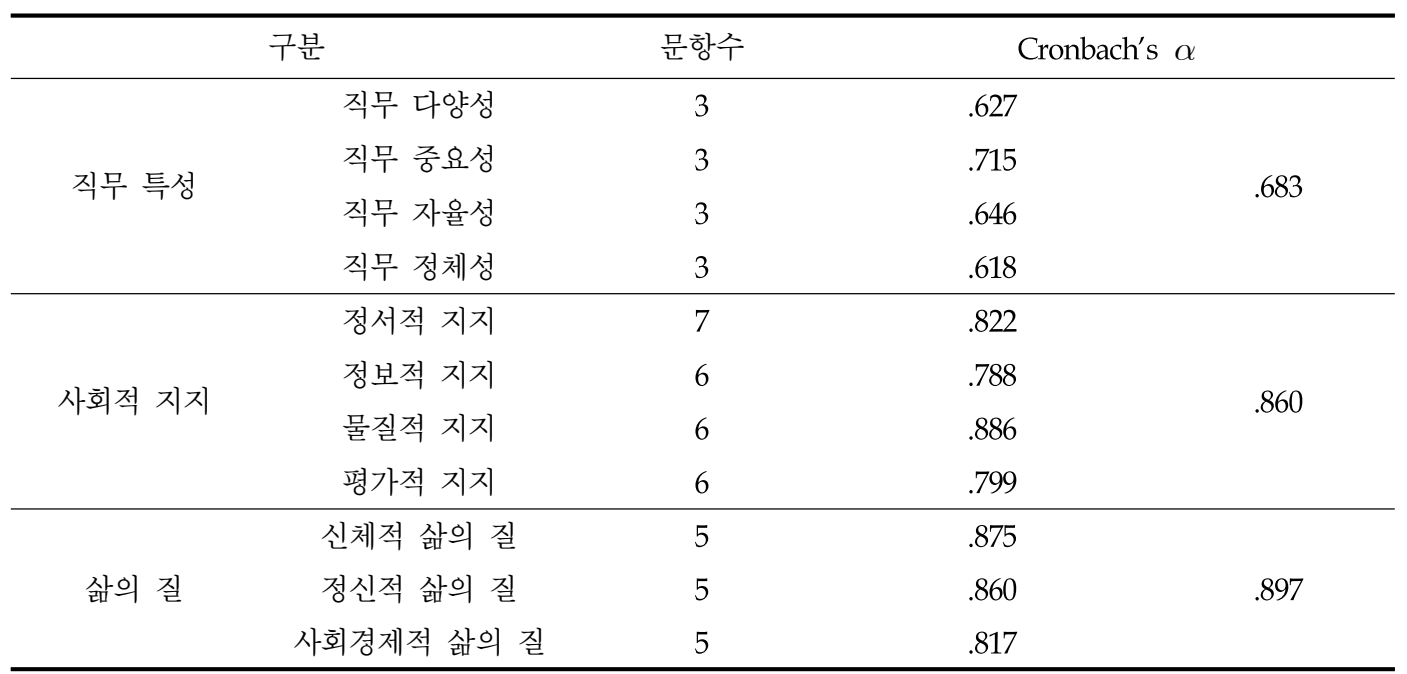

\section{4 자료처리 및 분석방법}

연구에 수집된 자료처리는 SPSS 22.0 프로그램을 사용하여 통계처리를 하였다. 그리고 유의수준 $5 \%$ 에서 검증을 실시하였다. 독거노인생활관리사의 인구사회학적 특성은 빈도분석을 실시하였다. 독거노인생활관리사의 각 도구에 대한 상관분석과 다중회귀분석을 실시하였다.

\section{3. 연구결과}

\section{1 인구사회학적 특성}

인구사회학적 특성에 대한 분석결과를 요약하면, 독거노인생활관리사의 대상자는 모두 여성인 것 으로 분석되었다. 연령은 50 대가 118 명 $67.8 \%$ )으로 가장 많은 것으로 조사되었으며, 40 대 43 명 $(24.7 \%), 30$ 대 8 명 $(4.6 \%), 60$ 대 이상 5명(2.9\%) 순으로 나타났다. 결혼 상태는 기혼이 162 명(93.1\%), 미혼이 12 명(6.9\%)으로 대부분 기혼인 것으로 조사되었다. 종교는 유 112 명 $(64.4 \%)$, 무 62명(35.6\%) 으로 종교가 있는 대상자가 더 많은 것으로 나타났다. 근무경력에서는 4년 이상-6년 미만 65명 (37.4\%)이 가장 많았으며, 1 년 이상-2년 미만이 52명(29.9\%), 8 년 이상 24 명(13.8\%), 2년 이상-4년 미 만 19명(10.9\%), 6년 이상-8년 미만 14 명 $(8.0 \%)$ 순으로 나타났다. 독거노인생활관리사의 인구사회학 적 특성에 대하여 살펴본 결과는 [표 2]와 같다. 
A Study on Mediating Effects of Social Supports between Job Characteristics and the Quality of Life of the Elderly Single Household Caregiver

[표 2] 인구사회학적 특성

[Table 2] Sociodemographic Characteristics

\begin{tabular}{|c|c|c|c|}
\hline \multirow{2}{*}{\multicolumn{2}{|c|}{ 구분 }} & \multicolumn{2}{|c|}{ 전체 $(\mathrm{N}=174)$} \\
\hline & & \multirow{3}{*}{$\begin{array}{c}\text { 빈도 } \\
0 \\
174\end{array}$} & \multirow{3}{*}{$\begin{array}{c}\text { 비율(\%) } \\
0.0 \\
100.0\end{array}$} \\
\hline & 남자 & & \\
\hline 성멀 & 여자 & & \\
\hline \multirow{4}{*}{ 연령 } & 30대 & 8 & 4.6 \\
\hline & 40대 & 43 & 24.7 \\
\hline & 50대 & 118 & 67.8 \\
\hline & 60 대 이상 & 5 & 2.9 \\
\hline \multirow{2}{*}{ 결혼 상태 } & 미혼 & 12 & 6.9 \\
\hline & 기혼 & 162 & 93.1 \\
\hline \multirow{2}{*}{ 종교 } & 유 & 112 & 64.4 \\
\hline & 무 & 62 & 35.6 \\
\hline \multirow{5}{*}{ 근무경력 } & 1년 이상-2년 미만 & 52 & 29.9 \\
\hline & 2년 이상-4년 미만 & 19 & 10.9 \\
\hline & 4년 이상-6년 미만 & 65 & 37.4 \\
\hline & 6년 이상-8년 미만 & 14 & 8.0 \\
\hline & 8년 이상 & 24 & 13.8 \\
\hline
\end{tabular}

\section{2 주요 변수에 대한 기술통계}

\subsection{1 직무 특성에 대한 기술통계}

독거노인생활관리사의 주요 변수에 대한 측정 변수는 5점 척도로 측정하였으며, 직무 특성의 하위 요인별로 살펴보면, 직무 중요성 $(\mathrm{M}=3.88)$ 요인이 가장 높게 나타났으며, 직무 정체성 $(\mathrm{M}=3.64)$, 직무 자율성 $(\mathrm{M}=3.59)$, 직무 다양성 $(\mathrm{M}=3.38)$ 순으로 모두 평균 이상으로 나타났다. 독거노인생활관리사의 주요 변수에 대한 기술통계를 살펴본 결과는 [표 3]과 같다.

[표 3] 직무 특성에 대한 기술통계

[Table 3] Descriptive Statistics on Job Characteristics

\begin{tabular}{ccccccc}
\hline & 구분 & $\mathrm{N}$ & 최소값 & 최대값 & $\mathrm{M}$ & $\mathrm{SD}$ \\
\hline \multirow{4}{*}{ 직무 특성 } & 직무 다양성 & 174 & 1.00 & 4.60 & 3.38 & .56 \\
& 직무 중요성 & 174 & 1.80 & 5.00 & 3.88 & .53 \\
& 직무 자율성 & 174 & 2.00 & 5.00 & 3.59 & .60 \\
& 직무 정체성 & 174 & 2.00 & 4.80 & 3.64 & .49 \\
\hline
\end{tabular}




\subsection{2 사회적 지지에 대한 기술통계}

독거노인생활관리사의 주요 변수에 대한 측정 변수는 5 점 척도로 측정하였으며, 사회적 지지의 하 위요인별로 살펴보면, 정서적 지지 $(\mathrm{M}=3.88)$ 요인이 가장 높게 나타났으며, 평가적 지지 $(\mathrm{M}=3.87)$, 정 보적 지지 $(\mathrm{M}=3.73)$, 물질적 지지 $(\mathrm{M}=3.20)$ 순으로 모두 평균 이상으로 나타났다. 독거노인생활관리 사의 주요 변수에 대한 기술통계를 살펴본 결과는 [표 4]와 같다.

[표 4] 사회적 지지에 대한 기술통계

[Table 4] Descriptive Statistics on Social Support

\begin{tabular}{clccccc}
\hline & 구분 & $\mathrm{N}$ & 최소값 & 최대값 & $\mathrm{M}$ & $\mathrm{SD}$ \\
\hline \multirow{3}{*}{ 사회적 } & 정서적 지지 & 174 & 1.71 & 5.00 & 3.88 & .54 \\
지지 & 정보적 지지 & 174 & 2.17 & 5.00 & 3.73 & .61 \\
& 물질적 지지 & 174 & 1.00 & 5.00 & 3.20 & .83 \\
& 평가적 지지 & 174 & 2.00 & 5.00 & 3.87 & .58 \\
\hline
\end{tabular}

\subsection{3 삶의 질에 대한 기술통계}

독거노인생활관리사의 주요 변수에 대한 측정 변수는 5 점 척도로 측정하였으며, 삶의 질을 하위요 인별로 살펴보면, 정신적 삶의 질 $(\mathrm{M}=3.75)$ 요인이 가장 높게 나타났으며, 신체적 삶의 질 $(\mathrm{M}=3.63)$, 사회경제적 삶의 질 $(\mathrm{M}=3.59)$ 순으로 모두 평균 이상으로 나타난 것을 알 수 있다. 독거노인생활관 리사의 주요 변수에 대한 기술통계를 살펴본 결과는 [표 5]와 같다.

[표 5] 삶의 질에 대한 기술통계

[Table 5] Descriptive Statistics on Quality of Life

\begin{tabular}{ccccccc}
\hline & 구분 & $\mathrm{N}$ & 최소값 & 최대값 & $\mathrm{M}$ & $\mathrm{SD}$ \\
\hline \multirow{3}{*}{ 삶의 질 } & 신체적 & 174 & 2.00 & 5.00 & 3.63 & .53 \\
& 정신적 & 174 & 2.00 & 5.00 & 3.75 & .52 \\
& 사회경제적 & 174 & 2.00 & 5.00 & 3.59 & .59 \\
\hline
\end{tabular}

\section{3 변수 간의 상관관계}

독거노인생활관리사의 직무 특성, 사회적 지지, 삶의 질의 관련성을 살펴본 결과, 직무 특성과 사 회적 지지는 낮은 수준의 양의 상관관계를 지니고 있음을 알 수 있다 $(\mathrm{r}=.232 \sim .390, \mathrm{p}<.01)$. 그리고 
A Study on Mediating Effects of Social Supports between Job Characteristics and the Quality of Life of the Elderly Single Household Caregiver

사회적 지지와 신체적 삶의 질 $(\mathrm{r}=.340, \mathrm{p}<.01)$, 사회적 지지와 사회경제적 삶의 질 $(\mathrm{r}=.373, \mathrm{p}<.01)$ 도 낮은 수준의 양의 상관관계를 지니는 것으로 나타났다. 반면, 사회적 지지와 정신적 삶의 질은 다 소 높은 수준의 양의 상관관계를 지니는 것으로 확인되었다 $(\mathrm{r}=.443, \mathrm{p}<.01)$. 이러한 결과들은 각 상 관계수 값이 통계적 유의수준 하에서 변수들 간의 관계성이 있음을 보여주고 있는 것이다. 독거노 인생활관리사에 대한 주요 변수 간의 상관관계 분석결과는 [표 6]과 같다.

[표 6] 주요 변수 간의 상관관계

[Table 6] Correlation between Key Variables

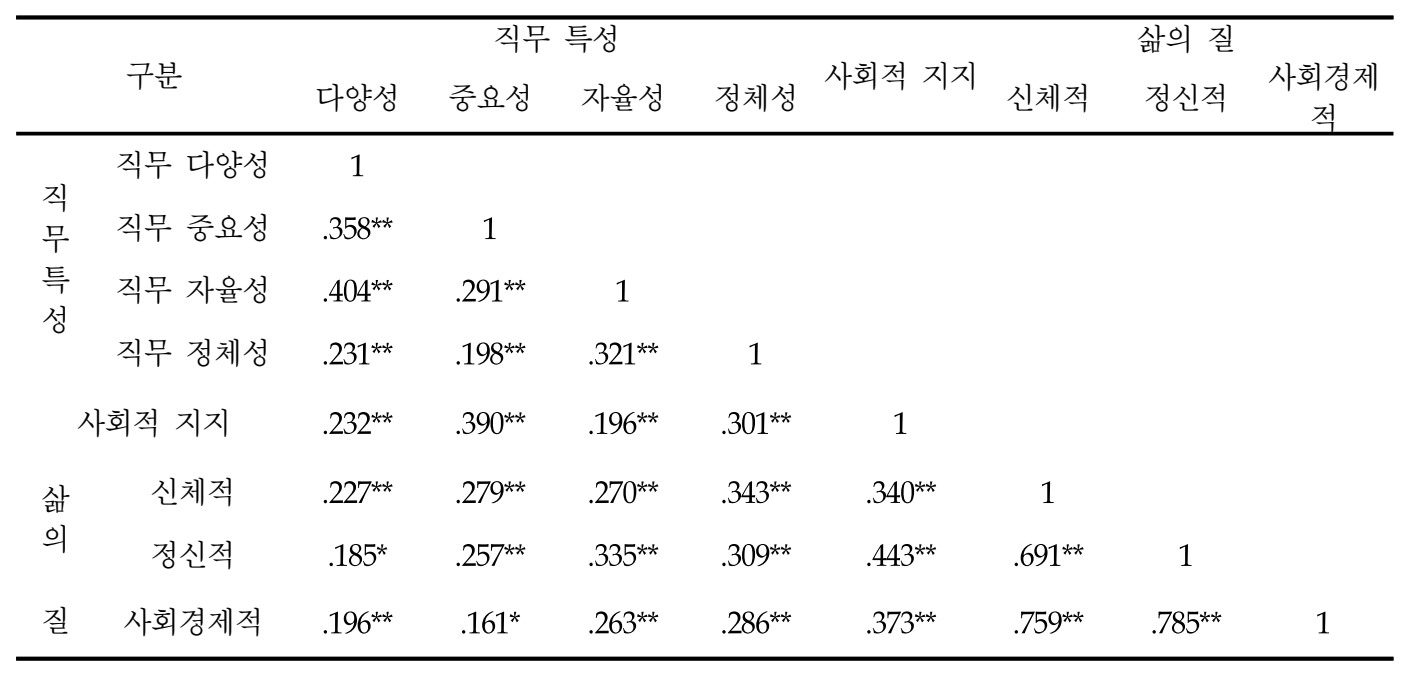

${ }^{*} \mathrm{p}<.05,{ }^{* *} \mathrm{p}<.01$

\section{4 독거노인생활관리사의 직무 특성이 삶의 질에 미치는 영향}

\subsection{1 직무 특성이 신체적 삶의 질에 미치는 영향}

독거노인생활관리사의 직무 특성과 신체적 삶의 질과의 관계에서 사회적 지지의 매개효과를 검증 하기 위하여 회귀분석을 실시하였다. 분석결과 모형의 적합도는 유의미한 것으로 나타났다. 1단계 에서 독립변수인 직무 특성이 매개변수인 사회적 지지에 미치는 유의한 영향관계를 알아본 결과, 직무 특성의 하위요인인 직무 중요성 $(\mathrm{t}=4.511, \mathrm{p}<.001)$, 직무 정체성 $(\mathrm{t}=3.050, \mathrm{p}<.01)$ 은 사회적 지지에 대해 통계적 유의수준 하에 유의한 정(+)적 영향을 미치는 것으로 나타났다. 또한 2단계에서 독립 변수인 직무 특성의 하위요인 중 직무 정체성 $(\mathrm{t}=4.249, \mathrm{p}<.01)$ 요인만 사회적 지지에 대해 통계적 유의수준 하에 유의한 정 $(+)$ 적 영향을 미치는 것으로 파악되었다. 3 단계에서는 매개변수인 사회적 지지를 투입한 결과 직무 정체성 $(\mathrm{t}=.110, \mathrm{p}<.05)$ 이 유의한 정 $(+)$ 적 영향을 미치는 것으로 나타났다. 또한 3 단계 직무 정체성의 표준화된 베타 값 $(\beta=254)$ 이 2단계에서 도출된 표준화된 베타 값( $\beta$ 

$=.319)$ 보다 작아져 매개효과가 있는 것으로 파악되었다. 따라서 직무 특성의 하위요인 중 직무 정 체성이 신체적 삶의 질에 미치는 영향 관계에서 사회적 지지는 부분 매개효과가 있는 것으로 나타 났다. 독거노인생활관리사의 직무 특성과 신체적 삶의 질과의 관계에서 사회적 지지의 매개효과를 살펴본 결과는 [표 7]과 같다.

[표 7] 독거노인생활관리사의 직무 특성과 신체적 삶의 질의 관계에서 사회적 지지의 매개효과

[Table 7] Mediating Effects of Social Support in the Relationship between Job Characteristics and Quality of Physical Life of the Elderly Single Household Caregiver

\begin{tabular}{|c|c|c|c|c|c|c|c|}
\hline \multirow[b]{2}{*}{ 단계 } & \multirow[b]{2}{*}{ 구분 } & \multicolumn{6}{|c|}{ 종속변수: 신체적 삶의 질 } \\
\hline & & B & $\beta$ & $\mathrm{R}^{2}$ & 수정된 $\mathrm{R}^{2}$ & $\mathrm{t}$ & $\begin{array}{l}\text { 공차 } \\
\text { 한계 }\end{array}$ \\
\hline \multirow{5}{*}{$\begin{array}{c}1 \text { 단계: } \\
\text { 독립 } \rightarrow \text { 매개 }\end{array}$} & 상수 & & & & & $3.489^{* *}$ & \\
\hline & 직무 다양성 & -.008 & -.009 & \multirow{4}{*}{.205} & \multirow{4}{*}{.186} & -.110 & .755 \\
\hline & 직무 중요성 & .350 & .340 & & & $4.511^{* * *}$ & .826 \\
\hline & 직무 자율성 & .025 & .028 & & & .354 & .732 \\
\hline & 직무 정체성 & .247 & .225 & & & $3.050^{* *}$ & .864 \\
\hline \multirow{5}{*}{$\begin{array}{c}\text { 2단계: } \\
\text { 독립 } \rightarrow \text { 종속 }\end{array}$} & 상수 & \multicolumn{2}{|c|}{1.722} & \multirow{5}{*}{.179} & \multirow{5}{*}{.159} & \multicolumn{2}{|l|}{$4.459^{* * *}$} \\
\hline & 직무 다양성 & .196 & .205 & & & 2.551 & .755 \\
\hline & 직무 중요성 & -.090 & -.089 & & & $-1.167^{* * *}$ & .826 \\
\hline & 직무 자율성 & .098 & .111 & & & 1.365 & .732 \\
\hline & 직무 정체성 & .342 & .319 & & & $4.249^{* *}$ & .864 \\
\hline \multirow{6}{*}{$\begin{array}{c}\text { 3단계: } \\
\text { 독립 · 매개 } \rightarrow \text { 종 } \\
\text { 속 }\end{array}$} & 상수 & \multicolumn{2}{|c|}{1.338} & & \multirow{6}{*}{.223} & $3.482^{* *}$ & \\
\hline & 직무 다양성 & .198 & .207 & & & $2.686^{* *}$ & .755 \\
\hline & 직무 중요성 & -.189 & -.188 & & & $-2.408^{*}$ & .737 \\
\hline & 직무 자율성 & .091 & .103 & .245 & & 1.315 & .731 \\
\hline & 직무 정체성 & .272 & .254 & & & $3.423^{* *}$ & .819 \\
\hline & 사회적 지지 & .284 & .289 & & & $3.848^{* * *}$ & .795 \\
\hline
\end{tabular}

${ }^{*} \mathrm{p}<.05, * * \mathrm{p}<.01, * * * \mathrm{p}<.001$

\section{4 .2 직무 특성이 정신적 삶의 질에 미치는 영향}

독거노인생활관리사의 직무 특성과 정신적 삶의 질과의 관계에서 사회적 지지의 매개효과를 검증 하기 위하여 회귀분석을 실시하였다. 분석결과 모형의 적합도는 유의미한 것으로 나타났다. 1단계 에서 독립변수인 직무 특성이 매개변수인 사회적 지지에 미치는 유의한 영향관계를 알아본 결과, 직무 특성의 하위요인인 직무 중요성 $(\mathrm{t}=.4 .511, \mathrm{p}<.001)$, 직무 정체성 $(\mathrm{t}=3.050, \mathrm{p}<.01)$ 은 사회적 지지에 대해 통계적 유의수준 하에 유의한 정 $(+)$ 적 영향을 미치는 것으로 나타났다. 또한 2 단계에서 독립 
A Study on Mediating Effects of Social Supports between Job Characteristics and the Quality of Life of the Elderly Single Household Caregiver

변수인 직무 특성의 하위요인 중 직무 자율성 $(\mathrm{t}=2.551, \mathrm{p}<.05)$ 은 1 단계에서 유의하지 않은 것으로 나타나 탈락된 요인으로 의미가 없으며, 직무 정체성 $(\mathrm{t}=2.846, \mathrm{p}<.01)$ 요인만 사회적 지지에 대해 통 계적 유의수준 하에 유의한 정(+)적 영향을 미치는 것으로 파악되었다. 3 단계에서는 매개변수인 사 회적 지지를 투입한 결과 직무 정체성 $(\mathrm{t}=1.855, \mathrm{p}>.05)$ 이 유의한 영향을 미치지 않는 것으로 나타났 다. 또한 3 단계 직무 정체성의 표준화된 베타 값 $(\beta=134)$ 이 2 단계에서 도출된 표준화된 베타 값 $(\beta$ $=$.208) 보다 작아져 매개효과가 있는 것으로 파악되었다. 따라서 직무 특성의 하위요인 중 직무 정 체성이 정신적 삶의 질에 미치는 영향 관계에서 사회적 지지는 완전 매개효과가 있는 것으로 나타 났다. 독거노인생활관리사의 직무 특성과 정신적 삶의 질과의 관계에서 사회적 지지의 매개효과를 살펴본 결과는 [표 8]과 같다.

[표 8] 독거노인생활관리사의 직무 특성과 정신적 삶의 질의 관계에서 사회적 지지의 매개효과

[Table 8] Mediating Effect of Social Support on Relationship between Job Characteristics and Quality of Mental Life of the Elderly Single Household Caregiver

\begin{tabular}{|c|c|c|c|c|c|c|c|}
\hline \multirow[b]{2}{*}{ 단계 } & \multirow[b]{2}{*}{ 구분 } & \multicolumn{6}{|c|}{ 종속변수: 정신적 삶의 질 } \\
\hline & & B & $\beta$ & $\mathrm{R}^{2}$ & 수정된 $R^{2}$ & $\mathrm{t}$ & $\begin{array}{l}\text { 공차 } \\
\text { 한계 }\end{array}$ \\
\hline \multirow{5}{*}{$\begin{array}{c}1 \text { 단계: } \\
\text { 독립 } \rightarrow \text { 매개 }\end{array}$} & 상수 & & & & & $3.489^{* *}$ & \\
\hline & 직무 다양성 & -.008 & -.009 & \multirow{4}{*}{.205} & \multirow{4}{*}{.186} & -.110 & .755 \\
\hline & 직무 중요성 & .350 & .340 & & & $4.511^{* * *}$ & .826 \\
\hline & 직무 자율성 & .025 & .028 & & & .354 & .732 \\
\hline & 직무 정체성 & .247 & .225 & & & $3.050^{* *}$ & .864 \\
\hline \multirow{5}{*}{$\begin{array}{c}\text { 2단계: } \\
\text { 독립 } \rightarrow \text { 종속 }\end{array}$} & 상수 & \multicolumn{2}{|c|}{1.615} & \multirow{5}{*}{.179} & \multirow{5}{*}{.160} & $4.271^{* * *}$ & \\
\hline & 직무 다양성 & .042 & .045 & & & .565 & .755 \\
\hline & 직무 중요성 & .136 & .138 & & & 1.801 & .826 \\
\hline & 직무 자율성 & .180 & .208 & & & $2.551^{*}$ & .732 \\
\hline & 직무 정체성 & .225 & .213 & & & $2.846^{* *}$ & .864 \\
\hline \multirow{6}{*}{$\begin{array}{c}\text { 3단계: } \\
\text { 독립· 매개 } \rightarrow \text { 종 } \\
\text { 속 }\end{array}$} & 상수 & \multicolumn{2}{|c|}{1.160} & & \multirow{6}{*}{.255} & $3.147^{* *}$ & \\
\hline & 직무 다양성 & .045 & .048 & & & .640 & .755 \\
\hline & 직무 중요성 & .019 & .019 & & & .246 & .737 \\
\hline & 직무 자율성 & .171 & .198 & .277 & & $2.579 * *$ & .731 \\
\hline & 직무 정체성 & .142 & .134 & & & 1.855 & .819 \\
\hline & 사회적 지지 & .337 & .350 & & & $4.761^{* * *}$ & .795 \\
\hline
\end{tabular}




\subsection{3 직무 특성이 사회경제적 삶의 질에 미치는 영향}

독거노인생활관리사의 직무 특성과 사회경제적 삶의 질과의 관계에서 사회적 지지의 매개효과를 검증하기 위하여 회귀분석을 실시하였다. 분석결과 모형의 적합도는 유의미한 것으로 나타났다. 1 단계에서 독립변수인 직무 특성이 매개변수인 사회적 지지에 미치는 유의한 영향관계를 알아본 결 과, 직무 특성의 하위요인인 직무 중요성 $(\mathrm{t}=.4 .511, \mathrm{p}<.001)$, 직무 정체성 $(\mathrm{t}=3.050, \mathrm{p}<.01)$ 은 사회적 지 지에 대해 통계적 유의수준 하에 유의한 정 $(+)$ 적 영향을 미치는 것으로 나타났다. 또한 2단계에서 독립변수인 직무 특성의 하위요인 중 직무 정체성 $(\mathrm{t}=3.039, \mathrm{p}<.01)$ 요인만 사회적 지지에 대해 통계 적 유의수준 하에 유의한 정 $(+)$ 적 영향을 미치는 것으로 파악되었다. 3 단계에서는 매개변수인 사회 적 지지를 투입한 결과 직무 정체성 $(\mathrm{t}=2.166, \mathrm{p}<.05)$ 이 유의한 정 $(+)$ 적 영향을 미치는 것으로 나타났 다. 또한 3 단계 직무 정체성의 표준화된 베타 값 $(\beta=164)$ 이 2단계에서 도출된 표준화된 베타 값( $\beta$ $=.235$ ) 보다 작아져 매개효과가 있는 것으로 파악되었다. 따라서 직무 특성의 하위요인 중 직무 정 체성이 사회경제적 삶의 질에 미치는 영향 관계에서 사회적 지지는 부분 매개효과가 있는 것으로 나타났다. 독거노인생활관리사의 직무 특성과 사회경제적 삶의 질과의 관계에서 사회적 지지의 매 개효과를 살펴본 결과는 [표 9]와 같다.

[표 9] 독거노인생활관리사의 직무 특성과 사회경제적 삶의 질의 관계에서 사회적 지지의 매개효과

[Table 9] Mediating Effect of Social Support in Relationship between Job Characteristics and Quality of Socioeconomic Life of the Elderly Single Household Caregiver

\begin{tabular}{|c|c|c|c|c|c|c|c|}
\hline \multirow[b]{2}{*}{ 단계 } & \multirow[b]{2}{*}{ 구분 } & \multicolumn{6}{|c|}{ 종속변수: 사회경제적 삶의 질 } \\
\hline & & B & $\beta$ & $\mathrm{R}^{2}$ & 수정된 $\mathrm{R}^{2}$ & $\mathrm{t}$ & $\begin{array}{l}\text { 공차 } \\
\text { 한계 }\end{array}$ \\
\hline \multirow{5}{*}{$\begin{array}{c}\text { 1단계: } \\
\text { 독립 } \rightarrow \text { 매개 }\end{array}$} & 상수 & & & & & $3.489^{* *}$ & \\
\hline & 직무 다양성 & -.008 & -.009 & \multirow{4}{*}{.205} & \multirow{4}{*}{.186} & -.110 & .755 \\
\hline & 직무 중요성 & .350 & .340 & & & $4.511^{* * *}$ & .826 \\
\hline & 직무 자율성 & .025 & .028 & & & .354 & .732 \\
\hline & 직무 정체성 & .247 & .225 & & & $3.050 * *$ & .864 \\
\hline \multirow{5}{*}{$\begin{array}{c}\text { 2단계: } \\
\text { 독립 } \rightarrow \text { 종속 }\end{array}$} & 상수 & & & \multirow{5}{*}{.130} & \multirow{5}{*}{.110} & $3.411^{* *}$ & \\
\hline & 직무 다양성 & .135 & .126 & & & 1.524 & .755 \\
\hline & 직무 중요성 & .037 & .032 & & & .412 & .826 \\
\hline & 직무 자율성 & .125 & .127 & & & 1.518 & .732 \\
\hline & 직무 정체성 & .282 & .235 & & & $3.039 * *$ & .864 \\
\hline \multirow{6}{*}{$\begin{array}{c}\text { 3단계: } \\
\text { 독립 · 매개 } \rightarrow \text { 종 } \\
\text { 속 }\end{array}$} & 상수 & & & & & $2.391^{*}$ & \\
\hline & 직무 다양성 & .137 & .129 & \multirow{5}{*}{.208} & \multirow{5}{*}{.184} & 1.626 & .755 \\
\hline & 직무 중요성 & -.083 & -.074 & & & -.921 & .737 \\
\hline & 직무 자율성 & .117 & .118 & & & 1.475 & .731 \\
\hline & 직무 정체성 & .197 & .164 & & & $2.166^{*}$ & .819 \\
\hline & 사회적 지지 & .342 & .312 & & & $4.050^{* * *}$ & .795 \\
\hline
\end{tabular}




\section{A Study on Mediating Effects of Social Supports between Job Characteristics and the Quality of Life of the Elderly Single Household Caregiver}

\section{4. 결론 및 제언}

본 연구에서는 독거노인생활관리사의 직무 특성과 삶의 질과의 관계에서 사회적 지지의 매개효과 에 대하여 분석하였다. 분석결과를 토대로 구체적으로 논의하면 다음과 같다.

첫째, 독거노인생활관리사의 직무 특성의 하위요인 중 직무 정체성이 신체적 삶의 질에 미치는 영향 관계에서 사회적 지지는 부분 매개효과가 있는 것으로 나타났다. 반면, 직무 특성의 하위요인 중 직무 다양성, 직무 중요성, 직무 자율성 요인과 신체적 삶의 질과의 관계에서 사회적 지지는 매 개효과가 없는 것으로 나타났다. 이는 독거노인생활관리사의 직무 특성의 하위요인 중 직무 정체 성 요인이 높을수록 신체적 삶의 질이 높아지며, 이때 사회적 지지는 부분매개 역할을 한다는 것 을 의미하는 것이다. 이러한 결과는 유아 교사의 삶의 만족도에 직무소진, 사회지지, 인생관, 임파 워먼트는 직접적인 영향을 미치고, 사회적 지지는 인생관과 임파워먼트를 매개하여 삶의 만족도에 간접적 영향을 미친다는[14] 연구 결과를 지지한다. 또한, 소방 공무원의 직무 스트레스와 삶의 질 사이에서 사회적 지지가 부분 매개하는 것으로 나타난[15] 연구와 일치하였다. 즉, 직무 정체성은 신체적 삶의 질에 영향을 미치고, 이들 사이에 사회적 지지는 간접적으로 영향을 미치는 것으로 나타났다. 이러한 연구결과를 바탕으로 독거노인생활관리사의 신체적 삶의 질을 증진시키기 위한 개선방안이 필요하다.

둘째, 독거노인생활관리사의 직무 특성의 하위요인 중 직무 정체성이 정신적 삶의 질에 미치는 영향 관계에서 사회적 지지는 완전 매개효과가 있는 것으로 나타났다. 반면, 직무 특성의 하위요인 중 직무 다양성, 직무 중요성, 직무 자율성 요인과 정신적 삶의 질과의 관계에서 사회적 지지는 매 개효과가 없는 것으로 나타났다. 이는 독거노인생활관리사의 직무 특성의 하위요인 중 직무 정체 성 요인이 높을수록 정신적 삶의 질이 높아지며, 이 때 사회적 지지는 완전 매개 역할을 한다는 것을 의미하는 것이다. 이러한 결과는 상사 지지가 요양보호사의 심리적인 삶의 질에 미치는 영향 에서 요양보호사의 자기효능감은 매개역할을 하였다는[7] 연구와 일치하는 것으로 나타났다. 또한 지각된 사회적 지지는 청소년의 긍정적 정서 조절과 삶의 만족도의 관계에서 완전매개를 하는 것 으로 나타난[16] 연구와 동일한 것으로 확인되었다. 즉, 직무 정체성은 특성이 정신적 삶의 질에 영향을 미치고, 이들 사이에 사회적 지지는 완전매개를 하는 것으로 확인되었다. 이러한 연구결과 를 바탕으로 독거노인생활관리사의 정신적 삶의 질 향상을 위한 프로그램 개발 및 개입이 필요함 을 시사한다.

셋째, 독거노인생활관리사의 직무 특성의 하위요인 중 직무 정체성이 사회경제적 삶의 질에 미 치는 영향 관계에서 사회적 지지는 부분 매개효과가 있는 것으로 나타났다. 반면, 직무 특성의 하 위요인 중 직무 다양성, 직무 중요성, 직무 자율성 요인과 사회경제적 삶의 질과의 관계에서 사회 적 지지는 매개효과가 없는 것으로 나타났다. 이는 독거노인생활관리사의 직무 특성의 하위요인 중 직무 정체성 요인이 높을수록 사회경제적 삶의 질이 높아지며, 이 때 사회적 지지는 부분매개 
역할을 한다는 것을 의미하는 것이다. 이러한 결과는 상사 지지는 요양보호사의 환경적인 삶의 질 에 동료 지지는 사회 삶의 질에 영향을 미친다는[7] 연구와 의미적으로 일치하였다. 이러한 연구결 과를 바탕으로 독거노인생활관리사가 독거노인을 위한 노인돌봄기본서비스, 독거노인 응급안전 돌 봄서비스를 수행하는 과정에서 삶의 질에 부정적인 영향을 받지 않도록 특별한 대책이 필요하다.

이상의 논의된 결과를 토대로 다음과 같이 제언하고자 한다.

첫째, 독거노인생활관리사의 직무 정체성은 신체적 삶의 질에 정 $(+)$ 적인 영향을 미치는 것으로 나타났다. 또한, 이들 사이에 사회적 지지는 간접적으로 영향을 미치는 것으로 나타났다. 이에, 독 거노인 대상으로 업무를 수행하는 과정에서 직무 특성요인 중 직무 정체성의 개선 방안이 필요하 다. 신체적 삶의 질에 있어서 가장 중요한 주체는 독거노인생활관리사이므로 과업달성을 위해 직 무 정체성을 강화시킬 필요가 있다. 독거노인생활관리사의 신체적 삶의 질을 향상시키기 위해서 이들의 직무 능력의 향상과 직무 정체성 개발을 도모하여 삶의 만족도를 높이고자 하는 시도가 필 요하다.

둘째, 독거노인생활관리사의 직무 특성의 직무정체성 요인이 높을수록 정신적 삶의 질과 사회 경제적 삶의 질이 높아지며, 이들 사이에서 사회적 지지는 매개변수로 확인되었다. 이는 독거노인 생활관리사가 독거노인에게 서비스를 수행하는 과정에서 직무정체성으로 인해 야기될 수 있는 문 제에 관심을 기울일 필요가 있다. 또한, 독거노인생활관리사의 직무 정체성 향상 원인이 무엇인지 를 파악하는 것과 직무정체성 향상을 통해 정신적 삶의 만족도와 사회경제적 삶의 질을 높이고자 하는 시도와 독거노인 정책 추진에 따른 수행 인력의 전문성과 처우에 관한 연구가 필요하다.

향후 심리적 자본과 삶의 질에 대한 연구를 통한 독거노인생활관리사의 직무만족도 향상을 모 색할 필요성이 있다.

\section{References}

[1] G. S. Kim, The Effects of Social Support of Parents of Children with Disabilities on Family Health : Moderating Effect of Self-Esteem, Dongbang Culture University, Doctoral Dissertation, (2017)

[2] B. Y. Kim, A Study on the Effects of Job Characteristics and Organizational Justice on Organizational Commitment, Organizational Citizenship Behavior, and Union Related Behaviors Orientation, Uiduk University, Doctoral Dissertation, (2017)

[3] Kwon Seong-min, Kim Lee-young, Choi Yoon-hee, A Study on the variables affecting the Satisfaction with Life of the Early Childhood Teachers: Focusing on Burnout, Social Support, Satisfaction with Life, Empowerment, Life Stance, Journal of Public Society, (2019), Vol.9, No.1, pp.85-124.

[4] Kim Young-ae, Kim Moon-gyeom, Research on the Effects of Transformational Leadership on Organizational Effectiveness: Whether Individuals Around the Moderating Effects of the Accident Type, Journal of the Korea Contents Association, (2017), Vol.17, No.6, pp.351-361. 
[5] Kim Yun-shin, Lee Cheol-min, Namgung Sun-ju, Kim Hye-kyung, A Study on the Social Networks Effectiveness to Prevent the Lonely Death of the Elderly who Live Alone, Journal of Social Science, (2011), Vol.50, No.2, pp.143-169.

[6] Kim Jeong-hee, Kim Hae-ok, Hyun Sung-hyup, A study on the effect of job environment factors of cabin crew on their quality of work life and the quality of life, Korean Journal of Hospitality and Tourism, (2019), Vol.28, No.3, pp.19-33.

[7] Kim Jae-hee, Kim Wook, The Effect of Emotional Labour on Burnout and the Moderating Effect of Professional Competency of Life Managers for the Elderly Living Alone in Seoul, Seoul Studies, (2015), Vol.16, No.4, pp.193-214.

[8] T. H. Gu, Influence of social workers' job characteristics on quality of life in social welfare facilities-Focusing on moderating effects of self-efficacy-, Daegu Haany University, Doctoral Dissertation, (2017)

[9] Kim Hyungki, The Effects of the Stress of Elderly People Living Alone in Urban Areas on the Quality of Life : With a Focus on the Mediating Effect of Social Support, Journal of Korea Academia-Industrial cooperation Society, (2017), Vol.18, No.12, pp.443-451, DOI : 10.5762/KAIS.2017.18.12.443

[10] Noh Jae-cheol, Ko Jun-ki, Current Status and Problems of Support Polices and Legal Improvement Devices for the Aged Living Alone, The Journal of the Korea Contents Association, (2013), Vol.13, No.1, pp.257-268, https://doi.org/10.5392/JKCA.2013.13.01.257

[11] Mi Rim Lee, Effects of Social Support on the Relationships between Perceived Stress and Psychological Burnout of Suicide Prevention Counselor, The Journal of the Korea Contents Association, (2014), Vol.14, No.2, pp.308-318, https://doi.org/10.5392/JKCA.2014.14.02.308

[12] Yoon Myeong-sook, Kim Seong-hye, Mediating Effects of Depression and Social Support between the Relationship Job Stress and Quality of Life among Firefighters, Mental Health \& Social Work, (2014), Vol.42, No.2, pp.5-34, UCI : G704-000500.2014.42.2.001

[13] Lim Young-ah, Cho Young-chae, Covariance Structure Analysis of the Influence of Social Support, Physical and Mental Health Status on Quality of Life among the Elderly at Care Facilities, Journal of Korea Academia-Industrial cooperation Society, (2017), Vol.18, No.8, pp.210-220.

[14] Won Young-hee, Park Jun-ki, The Influence of Job Stress of Life Manager for Elderly People Living Alone on Job Satisfaction: Focused on the Mediating Effect of Self-Efficacy, Journal of community welfare, (2014), Vol.49, pp.403-427.

[15] KeunHong Kim, Hyegyung Kang, kyungin lee, Jeong-yeon Kim, The Status of Managing Posttraumatic Stress in Life Managers for Elderly People Living Alone and Measures for its Improvement: Focusing on Employees in Seoul, Journal of the Korea Gerontological Society, (2017), Vol.37, No.2, pp.293-308.

[16] Jung Moon-kyung, The Mediating Effects of Perceived Social Support and Social Competence on the Relationship between Emotional Regulation in Adolescents and Life Satisfaction, Studies on Korean Youth, (2014), Vol.21, No.12, pp.49-72, UCI : G704-000387.2014.21.12.002 